\author{
Corpus \\ $14 \mid 2015$ \\ Constitution et usage de corpus en linguistique \\ berbère
}

The interplay of style, information structure and definiteness: Double indirect objects in Figuig Berber narratives

Maarten Kossmann

(2) OpenEdition

Journals

Electronic version

URL: http://journals.openedition.org/corpus/2615

ISSN: $1765-3126$

Publisher

Bases; corpus et langage - UMR 6039

Printed version

Date of publication: 1 January 2015

Number of pages: $59-80$

ISBN: 1 638-9808

ISSN: 1638-9808

Electronic reference

Maarten Kossmann, «The interplay of style, information structure

and definiteness: Double indirect objects

in Figuig Berber narratives », Corpus [Online], 14 | 2015, Online since 29 August 2017, connection on 08 September 2020. URL : http://journals.openedition.org/corpus/2615

This text was automatically generated on 8 September 2020

(c) Tous droits réservés 


\title{
The interplay of style, information structure and definiteness: Double indirect objects in Figuig Berber narratives
}

\author{
Maarten Kossmann
}

1 All Berber languages have a category indirect object, which is marked differently from other objects. Moreover, in most of them, indirect objects, different from other objects, allow for a construction known as "clitic doubling", in which the same referent is expressed both lexically and pronominally. In this article, I shall study the contexts of clitic doubling in the Berber variety spoken in the oasis of Figuig in eastern Morocco. This language has been described by several authors, most notably Saa (2010, originally 1995), Kossmann (1997), Ben-Abbas (2003), Sahli (2008) and Benamara (2013). While doubling of indirect objects is sometimes mentioned, none of these sources provide an account of the distribution of the construction. There is no tradition of writing Figuig Berber, but a number of texts have been published, mostly in an academic context (e.g., Benamara 2011; Kossmann 2000: 104-125). The present article is based on one text genre, traditional narratives, ${ }^{2}$ and it is impossible to say to what extent the features analyzed here are specific to this genre or represent more general tendencies, also found, for instance, in conversational style.

\section{Indirect object in Berber}

2 In Figuig Berber, like in the other Berber languages, the indirect object has different expressions before nouns and with pronouns. Before nouns, it is expressed by a prepositional phrase using $i{ }^{3}$ while pronominalization is realized by means of a special pronoun. This pronoun is part of the verbal clitics which, depending on their syntactic 
context, may stand after or before the verb. The following examples illustrate this basic structure:

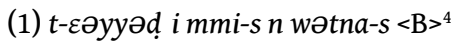

3SG:F-call:PV IO son-3sG of sister-3sG

'she called the son of her sister'

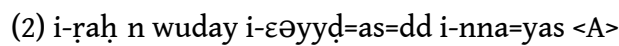

3SG:M-go:PV to Jew:AS 3SG:M-call:PV=3SG:IO=VENT 3SG:M-say: PV=3SG:IO

'he went to a Jew, he called him and said to him'

The indirect object pronouns are morphologically different from direct object pronouns, and resemble the series of bound pronominal forms used after prepositions, compare the forms of the third person singular bound pronouns (simplified, for a full overview, see Kossmann 1997: 177-185):

Table 1: Bound 3sg pronouns

\begin{tabular}{|l|l|l|l|}
\hline & Direct object & Indirect object & after the preposition (a)kid- 'with' \\
\hline $3 \mathrm{SG}: \mathrm{M}$ & $s s \sim t \sim i$ & as & $-s$ \\
\hline $3 \mathrm{SG}: \mathrm{F}$ & $t t \sim i t$ & as & $-s$ \\
\hline
\end{tabular}

Based purely on morphology, it would be possible to analyze most indirect object pronouns as prepositions, with an allomorphy between $i$ and $a$, i.e., $a s=a-s$ (cf. Bentolila 1981: 214). This is problematic on the morphosyntactic level, as the indirect object pronoun has different syntactic behavior than prepositions with pronominal suffixes. In the first place, prepositions with pronominal suffixes are the last member of the clitic cluster, following other clitics (example 3), while indirect object clitics are the first in the cluster (example 4), cf.

(3) iwa t-urow=dd=akid $-\partial s<\mathrm{A}>$

well 3sG:F-give.birth:PV=VENT=with-3SG

'well she got a child with him'

(4) $t$-urw $=a s ̌=d d ~ Q \partial r n f \partial t t+t a<A>$

3SG:F-give.birth:PV=2SG:M:IO=VENT Goldhorn

'she has given birth for you to Goldhorn'

5 Moreover, indirect objects allow for a construction, impossible with any other preposition, in which the preposition $i$ is followed by a free pronoun, e.g.

(5) awy=axdd wala i nəšni idžən <0>

bring:AO:IMPTV:PL=1SG:IO also IO we one:M

'bring (us) one to us too!'

(6) $u s ̌=i=t \partial t=d d$ i nətš! $<\mathrm{D}>$

give:AO:IMPTV:SG=1SG:IO=3SG:F:DO=1SG:IO IO I

'give it to me'

Indirect objects convey that the object is involved in the event but only indirectly or partly affected by it. ${ }^{5}$ This has different implications with verbs of different semantic 
classes. In transfer verbs, the indirect object is the participant to(wards) which the transfer takes place, i.e., basically the recipient, e.g.

(7) $y$-uš=as ləḥwayəž $n n-\partial s<Z>$

3SG:M-give:PV=3SG:IO clothes of-3SG

'he gave her her clothes'

7 This is different from locational constructions, in which the location towards which the transfer takes place is not involved in the event, cf. the difference between the following two examples with awəy 'to carry toward'. In example (8), the transfer takes place towards a person, who-as the recipient-is involved in the action, while in example (9), the object tiddart 'house' is not involved, and the directional preposition $l$ is used:

(8) $u w y-\partial n t=a s=d d$ səbea $n$ tmollalin $<A>$

bring:PV-3PL:F=3SG:IO=VENT seven of eggs:AS

'they brought her seven eggs'

(9) $t$-iwy=it l tiddart $n n-\partial s<0>$

3SG:F-bring:PV=3SG:F:DO to house of:3SG

'she brought it to her house'

8 In verbs of speaking, the indirect object expresses the person towards whom the speech act is addressed, ${ }^{6}$ e.g.

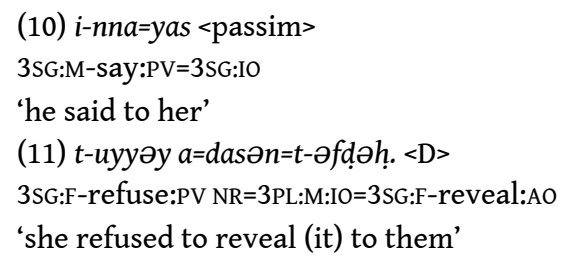

9 Verbs that describe actions manipulating only part of the object typically take the indirect object. ${ }^{7}$ When the manipulated part is also mentioned, such expressions can often be translated into English as possessives.

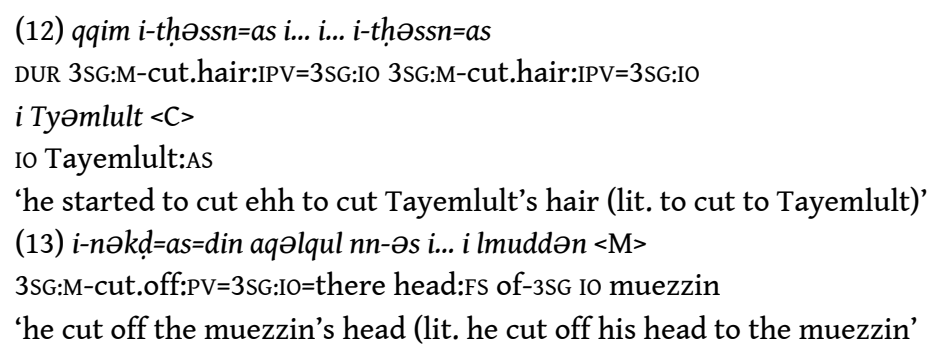

10 When the object is manipulated as a whole (or conceptualized as such), the direct object is used, as shown by the use of the direct object aqolqul 'head' in example (13).

11 Indirect objects are also used for the objects of non-visual perception events, such as "to understand (acoustically)", " to feel" and "to hear". 9

(14) $s$ tmara ay das=fəhm- $-\mathrm{n}<\mathrm{D}>$

with difficulty FOC 3SG:IO=understand:PV-3PL:M

'it was with difficulty that they understood her' (context: they listen to what is said by a girl whose tongue has been cut off) 
(15) yawkan $i$-səll=as ann $n$ nmalik $<\mathrm{A}>$

then 3SG:M-hear:PV=3SG:IO that of king

'then the king heard her'

Visual perception is constructed by means of a direct object, however:

(16) $t$-əmmatər yuma-s $<\mathrm{A}>$

3SG:F-see:Ao brother-3SG

'and she saw her brother'

Many verbs do not have an indirect object as an integral part of their event scheme, but can still be constructed with one. In such cases, the indirect object refers to a participant indirectly involved in, or affected by, the action. Most of such "ethical datives" have a benefactive or a malefactive connotation (cf. also Rapold 2010). Both connotations occur in the following passage, in which a father catches a bird for his son. The stepmother takes away the bird and kills it:

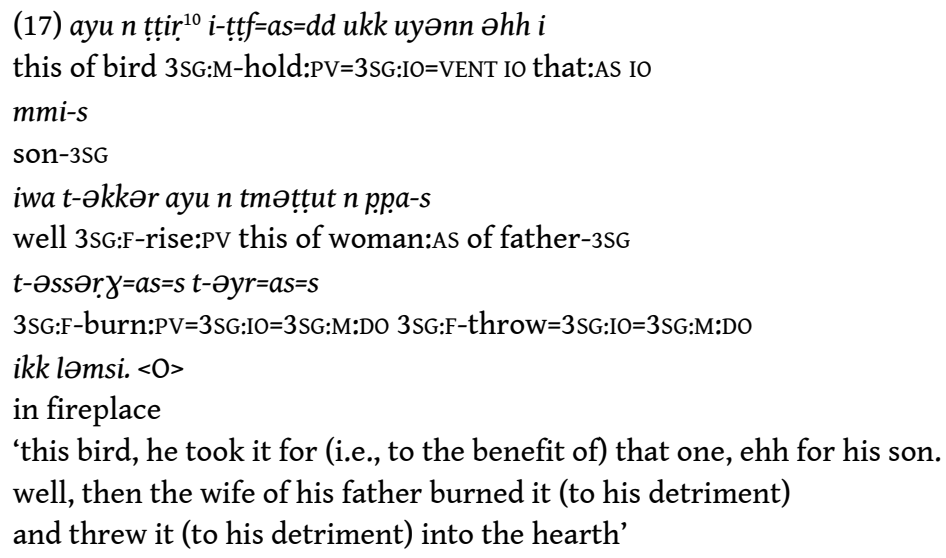

Often the term "dative" is used to refer to what is called the indirect object here (e.g., Rapold 2010). This indicates that the transfer function is the central meaning, and that other meanings are associated to this. In Berber, the indirect object can be defined by means of a reasonably coherent meaning: the indirectly or partly affected object. As this seems to cover the entire usage range of the category, there is no need to establish a more restricted prototypical meaning.

\section{Clitic doubling}

It is possible to have several indirect objects expressed with one single verb, e.g.

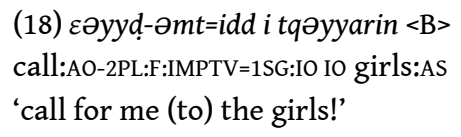

In example (18) there are two indirectly affected participants: the girls to whom the calling is directed, and the first person, to the benefit of whom the action is to be performed. It is not possible to have several indirect object pronouns in one single clitic complex. In the case that two different indirect objects are both pronominalized, one of them has to be demoted to a prepositional phrase using di- 'in' (Kossmann 1997: 217), ${ }^{11}$ e.g. 
(19) day z $\partial r s=i d d=d i-s<A>$

only slaughter:AO:IMPTV:SG=1SG:IO=in-3SG

'just slaughter it for me' construction, and not some type of extraposition or afterthought (cf. also Ouali 2011: 131-133).

24

(20) iwa uš-ənt=as ukk uyənn $n$ əhh uyənn $n$

well give:PV-3PL:F=3SG:IO IO that:AS of that:AS of

twəssart ayu n nəعwərt. <0>

old.-woman:As that of boy

'well, they gave that boy to that ehh that old woman'

In example (20) the old woman is referred to both pronominally (as) and by the prepositional phrase ukk uyənn $n$ twəssart 'to that old woman'.

This phenomenon is known in syntactic literature as "(indirect object) clitic doubling" (cf. the discussion in Souag 2014). Although it may be more correct to speak of "coreferent pronominal and lexical expression of indirect objects", I will use here the shorter and catchier term doubling.

21 In most cases, the prepositional phrase is within the same intonation contour as the verb. The lexical indirect object can be followed by other parts of the clause, e.g.

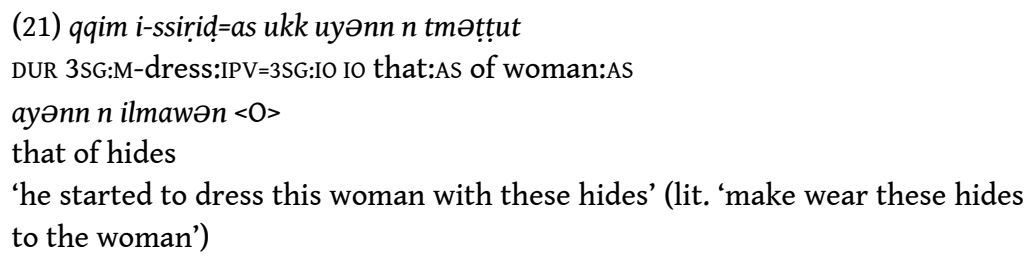

The construction also occurs within subordinate clauses, e.g.

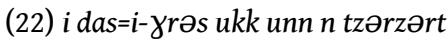

when 3SG:IO=3SG:M-slaughter:PV Io that:AS of gazelle

i-mmatər... $<\mathrm{A}>$

3SG:M-see:AO

'when he had slaughtered the gazelle, he saw that...'

(23) iwa y-awəy ann $n$ tənn $\partial h$ h

well 3sG:M-carry.to:Ao that of that:SG:F

das=ala=n-əssciš i lmalik $ə$ hh amənsi $<\mathrm{A}>$

3SG:IO=NR=SR-feed:AO IO king dinner:FS

'well, and he married the one ehh that would feed to the king ehh dinner'

One can conclude that the lexical indirect object is part of the core of the clause in this

Clitic doubling only refers to the use of two referential expressions of the indirect object in the core of the clause. This is different from topicalization, which is 
peripheral to the clause. Berber is basically Verb-initial, but has a topicalization position that precedes the sentence. The topic is syntactically, and often intonationally, kept apart from the core (cf. Lafkoui 2011: 119ff.), and the topic is referred to pronominally in the core, e.g.

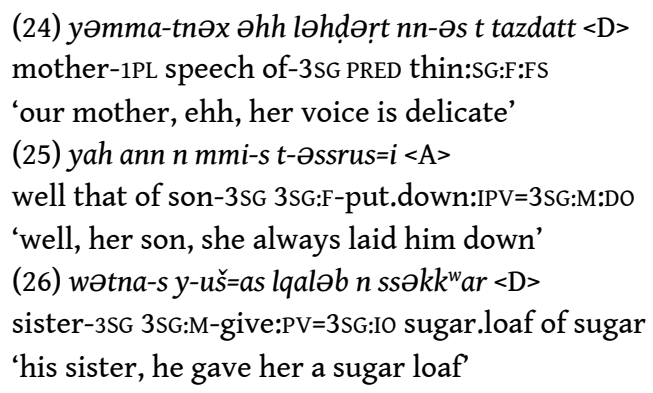

This is different from clitic doubling with indirect objects. While pronominal reference in topicalization is also found with direct objects and prepositional objects, this is impossible in the core of the clause, where only indirect object doubling is allowed.

Souag (2014) provides a comprehensive cross-dialectal overview of indirect object clitic doubling in Berber, as well as a historical account of its development. ${ }^{12}$ As he shows, the incidence of the phenomenon shows important variation within the Berber language family. In some languages it is almost obligatory with lexically expressed indirect objects, and can be considered a kind of agreement, e.g., in Siwa (Souag 2014). In other languages, such as Niger Tuareg, it is ungrammatical (Kossmann 2011: 122). Most Berber languages are in between: they allow for both constructions. Souag, mostly basing himself on published text corpora, concludes that, within the group allowing for both constructions, there are important dialectal differences as to their frequency. Some languages have it very often, e.g., Kabyle, while it is quite rare in others, such as Tashelhiyt (cf. also Rapold 2010: 353-354). Finally, studying the usage of clitic doubling, he concludes that, in addition to other correlations, there is an important lexical factor at work: the verb 'to say' is significantly more often used with clitic doubling than other verbs.

Inspired by these results, I decided to take a look at Figuig Berber, a language which allows for indirect object clitic doubling, but does not require it. To this purpose, I use two copora:

a. The K-corpus: Traditional narrations transcribed by the present author as a fieldwork corpus between 1990 and 1993. I have used the texts for which I have tape recordings, while dictated texts were left out. ${ }^{13}$

b. The B-corpus: Traditional narratives edited by Hassane Benamara in his Contes berbères de Figuig (Sud-est marocain) (Benamara 2011). The actual text of the narratives is not based on recordings (Benamara 2011: 5, n. 2), and sometimes strongly edited (Benamara 2011: 5). Still, the author managed to remain close to oral style, and the way the stories are told is similar to what I have in my recordings.

The K-corpus consists of 4.5 hours of recordings, amounting to close to 38,000 words, the B-corpus counts about 24,000 words (clitics are counted as separate words). The text genre is basically the same in both corpora. As for the dialect, Figuig Berber is not entirely homogeneous (Ben-Abbas 2003). The K-corpus mainly consists of stories from the village Zenaga, with the addition of a few stories told by a speaker from the village Elmaiz. The B-corpus is entirely from Zenaga, but shows a number of differences with 
the language of my recordings and of my spokesmen during fieldwork. This shows especially in the somewhat more archaic vocabulary used by Benamara (e.g. the use of aməšli instead of ləfdur for 'noon meal') and the allomorph $f$ before nouns of the implicative preposition, which is $s$ in my materials (Kossmann 1997: 223). ${ }^{14}$ Similar details of linguistic variation can be found within the K-corpus. The speakers in the Kcorpus are of different age and occupation. Quite an important number of the stories were told by elderly women, recorded for me by someone of their families. Another part of the corpus is spoken by younger male story tellers. In spite of these differences in detail, the two corpora can be considered representative for the language of traditional narrations in Figuig.

\section{Indirect object clitic doubling: stylistic variation}

The study of clitic doubling in the two corpora shows one very strong result. While doubling is common in the K-corpus, it is extremely rare in the B-corpus. This is most clearly shown by the incidence of clitic doubling with the verb ini 'to say'. ${ }^{15}$ In the Kcorpus, doubling is almost consistently used with this verb, with only two instances without it. In the B-corpus, on the other hand, only seven instances of doubling occur with this verb:

Table 2. Clitic doubling with ini 'to say'

\begin{tabular}{|l|l|l|l|l|l|}
\hline & Doubling & $\%$ & no Doubling & $\%$ & total \\
\hline K-corpus & 74 & $97 \%$ & 2 & $3 \%$ & 76 \\
\hline B-corpus & 7 & $9 \%$ & 74 & $91 \%$ & 81 \\
\hline
\end{tabular}

Something similar is found with other verbs. In verbs with animate indirect objects (inanimates are too infrequent in the texts to draw conclusions), about one third have doubling in the K-corpus. In the entire B-corpus, only eight of such instances are found:

Table 3. Clitic doubling with verbs other than ini 'to say'

\begin{tabular}{|l|l|l|l|l|l|}
\hline & Doubling & $\%$ & no Doubling & $\%$ & total \\
\hline K-corpus & 43 & $38 \%$ & 69 & $62 \%$ & 112 \\
\hline B-corpus & 8 & $7 \%$ & 100 & $93 \%$ & 108 \\
\hline
\end{tabular}

The differences between the two corpora are very clear: While indirect object clitic doubling is a common construction in the K-corpus, it is almost absent in the B-corpus. I assume that this is a stylistic difference. As mentioned above, Hassane Benamara has written down the stories on the basis of his own notes, but not with the help of recordings. His textualization therefore implies the low-pace, highly conscient way of language use typical of the writing process. Apparently, clitic doubling is suppressed to a high degree by this process. One cannot exclude that the author consciously chose 
not to use clitic doubling, maybe considering it an uneconomical way of expression. However that may be, his usage clearly shows that clitic doubling is not necessary in the language, and that a writer who approaches a vivid oral style in writing can freely leave out doubling.

This stylistic explanation for the difference between the two corpora is corroborated by the distribution of the few doubled indirect objects in Benamara's corpus. Six out of fifteen instances, including four instances of ini, come from one single tale, Nr. 47 (Lila d $\Sigma$ mer, p. 168-178). As Benamara explains in his notes, this particular tale was "recueilli" by Mahmoud Alehyane. It is not clear whether this also means that (part of) the textualization comes from Alehyane, but this is very well possible.

\section{Indirect object clitic doubling in the K-corpus: usage}

It is hardly possible, nor interesting, to study the distribution of clitic doubling in the $\mathrm{B}$-corpus, as it is almost entirely absent. The $\mathrm{K}$-corpus, on the other hand, provides a good basis for a more detailed analysis of the uses of clitic doubling.

There are a few contexts in which doubling is impossible. In the first place this is the case of reflexive indirect objects. In Figuig Berber, reflexives are made by means of a noun phrase using the nouns iman (only used for reflexives) or lxadər (lit. something like 'mind, liking') ${ }^{16}$ followed by a possessive. In spite of being lexical nouns syntactically, they are pronominal in reference, and their construction always includes a pronominal element. Apparently double pronominal reference is not possible here, and therefore doubling is not allowed, e.g.

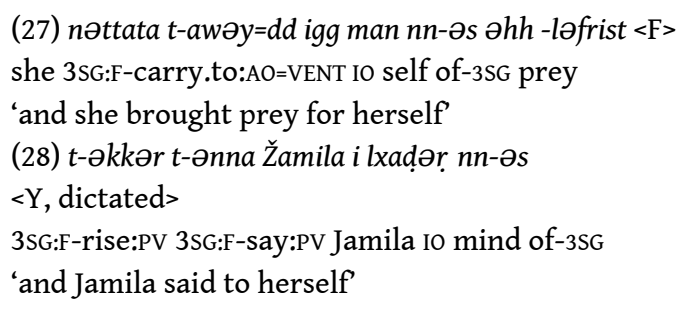

In the second place, doubled indirect objects are not attested with abstract or otherwise non-visual indirect objects, ${ }^{17}$ e.g.

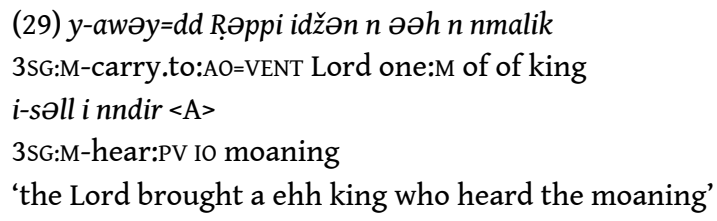

On the other hand, as shown above, clitic doubling is almost consistently found with the verb ini 'to say'. There are only very few instances where there is no doubling with this verb. The two following sentences represent all the cases that were found in the recordings:

(30) an i das=səll-ən middən, i... aḥbib until when 3SG:IO=hear:PV-3PL:M people friend:FS

i-qqar. ukk ḥbib <A>

3SG:M-say:IPV Io friend:AS 
'until when people heard it, and one friend said to the other'

(31) sad=ini-x ikk išš $n$ tbuțațt $<A>$

FUT=Say:AO-1SG IO one:F of fortune-teller:AS

'I shall say to a fortune-teller' ethical datives, e.g.

(34) $i-y y=a s=t t$ i tfunass nn-əs $\partial h$ h $i k k$

3SG:M-do:PV=3SG:IO=3SG:F:DO IO cow:AS of-3SG in

məz̧ $>a n<\mathrm{E}>$ (doubling)

ears

'he put it concerning his cow in the ears; i.e. he put it in the ears of his cow'

(35) rah-ən ttašr-ən ikk idžən $n$ užəllid <D>

(no doubling)

go:PV-3PL:M steal:IPV-3PL:M IO one:M of king:AS

'they went stealing to (the detriment of) a king'

$$
\text { distributional pattern, although as a tendency, and not as a strong condition. Clitic }
$$
doubling is mostly found in contexts where the referent is already known to the hearer, and present in the preceding discourse. In Berber narrations, such a situation can be overtly expressed by means of an anaphoric deictic expression. In Figuig, this expression is mostly a pre-nominal element ayu, ann or ayənn, ${ }^{18}$ linked to the noun by means of the possessive preposition $n$. It should be noted that the use of a deictic is by no means obligatory for referring to an old-information referent.

New referents in the discourse, on the other hand, only rarely have clitic doubling. New information is often indicated by a marker of indefiniteness, mostly idžən n... (feminine: $y i \check{s} 5$ n...). Like with old information, the use of a marker is not obligatory with new information. 
When looking at contexts that are explicitly old or new information, as shown by the use of $a(y \partial) n n$ and $i d z ̌ \partial n$, the following picture emerges:

Table 4. Doubling and no doubling in explicitely new and old information contexts

\begin{tabular}{|l|l|l|l|l|l|}
\hline & Doubling & $\%$ & no Doubling & $\%$ & total \\
\hline new information: idžən & 1 & $10 \%$ & 9 & $90 \%$ & 10 \\
\hline old information: $a(y \partial) n n$ & 16 & $67 \%$ & 8 & $33 \%$ & 24 \\
\hline total & 17 & & 17 & & 34 \\
\hline
\end{tabular}

Examples:

New information with doubling:

(36) an i i-wtu idžən n nbaḷu

until when 3sG:M-hit:PV one:M of ball

i-rraz=as ikk išš $n$ tacrabt

3SG:M-break:PV=3SG:IO IO one:F of Arab:SG:F

-tamərmitț $n n-\partial s<\mathrm{A}>19$

saucepan:FS of-3SG

'until when he hit the ball and broke to an Arab woman the saucepan'

47 New information without doubling:

(37) iwa y-isi=tt məskina ukk yis nn-əs

well 3SG:M-take:PV=3SG:F:DO poor:F in horse:AS of-3SG

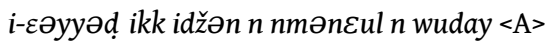

3sG:M-call:Pv IO one:M of damned of Jew:As

'well he took her, the poor one, on his horse and called a (damned) Jew'

Old information with doubling:

(38) qa $a=d a s \partial n=\gamma \partial r s-\partial x$ ukk unn $n$

entirely NR=3PL:M:IO=slaughter:AO-1SG IO that:AS of

-wufrišən $<\mathrm{A}>$

rams:AS

'I will slaughter all those rams'

Old information without doubling:

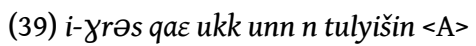

3SG:M-slaughter:Pv entirely to that:AS of bad:PL:F

'he killed all these bad women'

Clearly, clitic doubling is highly unusual when new information is explicitly expressed, while with explicitly old information doubling is more frequent than its absence.

When including cases where the question of old and new information has to be inferred from context, a similar pattern appears: 
Table 5. Doubling and absence of doubling according to information contexts (recorded texts)

\begin{tabular}{|l|l|l|l|l|l|}
\hline & Doubling & $\%$ & no Doubling & $\%$ & total \\
\hline new information & 2 & $6 \%$ & 30 & $94 \%$ & 32 \\
\hline old information & 33 & $58 \%$ & 24 & $42 \%$ & 57 \\
\hline general non-specific & 0 & $0 \%$ & 6 & $100 \%$ & 6 \\
\hline total & 35 & $37 \%$ & 60 & $63 \%$ & 95 \\
\hline
\end{tabular}

For seventeen instances (8x with doubling, 9 times without), I could not establish with confidence the information status of the dative element. "General non-specific" refers to cases that either give a general statement, which would be true of any referent, or a statement in which the identity of the referent is irrelevant, e.g.

(40) $u=d a m=n-\partial s m i h$ mta t-reyyd- $-\partial d$ i hədd $<0>$

NEG=2SG:F:IO=1PL-forgive:NP if 2SG-stop:PV-2SG IO -anybody

'we don't forgive you if you stop for somebody'

Thus, a pattern appears, in which doubling is strongly disfavored with new information, and slightly favored with old information. It should be noted, however, that in the latter case both constructions are possible, and sometimes occur in almost identical contexts. Thus, in a story where an ogress kills her own daughters, the first killing is described with doubling:

(41) $t$-əyy=as=dd amm=u ukk uyənn $n$ əhh $n$

3SG:F-do:PV=3SG:IO=VENT like=PROX Io that:AS of of

yəlli-s əhh tadəryalt. šštəxxxx <D>

daughter-3SG blind:SG:F:FS shhhtekhhh

'(she took a hot stick and stung it into her daughter) she did (to her) like this to that ehh blind daughter, shhhtekhhh'

The second killing, a few lines later, is described without doubling:

(42) dəxx t-əssitf=in ukk unn $n$

then 3SG:F-make.enter:PV=3PL:M:DO Io that:AS of

tu\&dimt. šštəxxxx <D>

handicapped:SG:F

'(she took other hot sticks) and then she stung them into that handicapped girl, shhhtekhhh'

Information structure is not the only feature that shows a correlation with the use of doubling. Several authors have defined this difference as pertaining to definiteness (Souag 2014; Guerssel 1995: 115-116; Ouali 2011: 131, the latter two apparently on the basis of native speaker intuitions). While there is much overlap between new/old information and indefinite/definite interpretation, the two are not equivalent. In fact, the texts abound in examples where definite nouns convey new information, e.g.

(43) ruh at=t-əqql-əd manəš i-lla 
go:AO:IMPTV:SG NR=2SG-look:AO-2SG how 3SG:M-be:PV

i-tekk i mmi-m $<\mathrm{A}>$

3SG:M-do:IPV IO son-2SG:F

'go and look what he is doing to your son'

In this example, mmi-m,'your son', has not been mentioned before by the cited speakeras part of a warning coming out of the blue for the addressee it can be considered entirely new information. However, mmi- $m$ is clearly definite, in the sense that it has unique, specific, reference known to the addressee, as the woman in question has only one son. In Figuig Berber, definiteness is not expressed grammatically. This does not necessarily mean that it is absent from the mind of the speakers, as almost all speakers of Figuig Berber are also fluent in Moroccan Arabic, which has overt expression of definiteness..$^{20} \mathrm{~A}$ categorization according to definiteness leads to the following results:

\begin{tabular}{|l|l|l|l|l|l|}
\hline & Doubling & $\%$ & no Doubling & $\%$ & total \\
\hline new info, indefinite & 1 & $5 \%$ & 20 & $95 \%$ & 21 \\
\hline new info, definite & 1 & $9 \%$ & 10 & $91 \%$ & 11 \\
\hline old info, definite & 33 & $60 \%$ & 22 & $40 \%$ & 55 \\
\hline general non-specific (indefinite) & 0 & $0 \%$ & 6 & $100 \%$ & 6 \\
\hline unclear information status, indefinite & 1 & $50 \%$ & 1 & $50 \%$ & 2 \\
\hline unclear information status, definite & 7 & $41 \%$ & 10 & $58 \%$ & 17 \\
\hline total indefinite & 2 & $7 \%$ & 27 & $93 \%$ & 29 \\
\hline total definite & 41 & $49 \%$ & 42 & $51 \%$ & 83 \\
\hline total & 43 & & 69 & & 112 \\
\hline
\end{tabular}

57 The results are almost identical to those of the information structure account. Indefinites and new information are only marginally used with dative doubling. Within definites, the slight preference for dative doubling with old information contexts is not mirrored by the figures for definiteness, which show an equal distribution over the two constructions. On the basis of these data, it is impossible to decide whether definiteness or information structure contributes most to the choice of construction; however, because of the stronger correlation between dative doubling and ayənn phrases (see above), the information structure account may present some more insight.

On the basis of these results, it is interesting to have a fresh look at ini 'to say'. As shown above there is a very strong tendency to have clitic doubling with this verb, a tendency also found in other Berber languages. The question is to what extent this is specific to quotative verbs and the constructions they involve (cf. Souag 2014 for a proposal), or a result of the information structure contexts where ini is mostly found in the text genre under scrutiny. On first sight, the lexical analysis seems to stand this test: Although ini is mostly used with indirect objects already present in the discourse, 
quite some attestations with clitic doubling involve protagonists that were not yet mentioned in the story. There is a caveat to this. In most cases, first mention of a protagonist implies the introduction of a new character into the mental image of the hearer. There are, however, cases where the presence of such a protagonist can be inferred from the larger context of the events described..$^{21}$ This seems to be the case with most instances of "new" information in ini. Many of these refer to persons that are expected to be around, e.g.

(44) (the king made a ring the size of the foot of a certain girl he is looking

for)

i-kkər i-nna=yas i tnəxdamt nn-əs:<0>

3SG:M-rise:PV 3SG:M-say:PV=3SG:IO IO servant:AS of-3SG

'and he said to his servant:22 (whom would fit this ring?)'

The servant is new information-no servant was mentioned before in the story-, but her presence can be deduced from the expected cultural context. Of course, all such cases could be considered "definite".

The corpus provides only very few examples of ini constructed with an overtly indefinite indirect object; in such cases dative doubling is still more often found than lack of doubling (for which, see ex. 33), e.g.

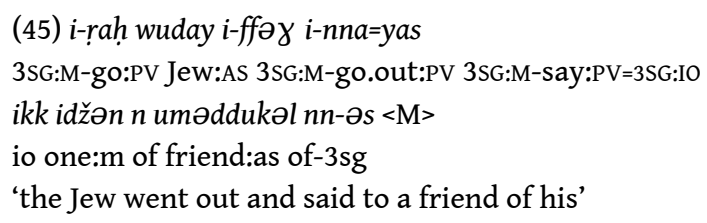

61 One may therefore question that the exceptional status of ini is purely a lexical feature, unrelated to the wider usage of the construction. Instead, it seem that its status is partly due to the type of contexts in which this verb is normally found. This does not mean that lexical information does not play a role at all. As shown above, verbs other than ini mark old information a bit more often by clitic doubling, but it is also possible not to have it. With ini, on the other hand, old information always leads to doubling. Thus, what is a tendency with other verbs is exceptionless with ini. It should be noted that this is only the case within the stylistic register reflected by the K-corpus. As mentioned above, the B-corpus ini only rarely has clitic doubling, irrespective of lexical features, definiteness, or information structure.

\section{Conclusion}

The use of indirect object clitic doubling in Figuig Berber is determined by a number of independent factors. The first factor is style, overriding everything else: there are some stylistic usages where doubling is strongly disfavored. This is found in the textualizations by Benamara, and may be related to the slow and speech-conscious process involved in writing down a language that has no tradition of writing. When looking at spoken registers, clitic doubling is quite common, and other factors play a role. In the first place, some syntactic contexts never show doubling, esp. pronominallike contexts, such as reflexives, and abstract indirect objects. In the remaining cases, there is a clear tendency related to information structure and/or definiteness: Clitic doubling is common when expressing old information and definites, while it is strongly 
disfavored in the expression of new information and indefinites. In addition to this, there is a lexical effect: what is a tendency with most verbs in the spoken corpus is exceptionless with ini 'to say', which, in the spoken corpus, always has doubling in contexts with old information.

\section{BIBLIOGRAPHY}

Ben-Abbas M. (2003). Variation et emprunts lexicaux. Étude sociolinguistique sur le parler amazigh de Figuig, PhD Thesis, Université Sidi Mohamed Ben Abdellah, Fes.

Benamara H. (2011). Contes berbères de Figuig (Sud-est marocain). Textes en berbère avec traductions en français. Cologne: Rüdiger Köppe.

Benamara H. (2013). Dictionnaire amazighe-français. Parler de Figuig et ses régions. Rabat: IRCAM.

Bentolila F. (1981). Grammaire fonctionnelle d'un parler berbère. Aït Seghrouchen d'Oum Jeniba (Maroc). Paris: SELAF.

Cadi K. (2006). Transitivité et diathèse en tarifite. Analyse de quelques relations de dépendances lexicale et syntaxique. Rabat: IRCAM.

Diessel H. (1999). Demonstratives: Form, Function, and Gram-maticalization. Amsterdam: John Benjamins.

Frajzyngier Z. and Munkaila M. (2004). Grammatical and Semantic Relations in Hausa. 'Point of View', 'Goal' and 'Affected Object'. Cologne: Rüdiger Köppe.

Guerssel M. (1995). "Berber clitic doubling and syntactic extraction”, Revue Quebecoise de Linguistique, 24/1: 111-33.

Kossmann M. (1997). Grammaire du parler berbère de Figuig (Maroc oriental). Paris and Louvain: Peeters.

Kossmann M. (2000). A Study of Eastern Moroccan Fairy Tales. Helsinki: Academia Scientiarum Fennica.

Kossmann M. (2011). A Grammar of Ayer Tuareg. Cologne: Rüdiger Köppe.

Kossmann M. "The use of the ventive marker dd in Figuig Berber narratives", Nordic Journal of African Studies, 23/4: 241-291.

Kossmann M. (fc.-a). “Deixis in Figuig Berber narrative texts”, Folia Orientalia, 52: 199-228.

Kossmann M. (fc.-b). “On word order in Figuig Berber narratives: The uses of pre- and postverbal lexical subjects”, to appear in Wiener Zeitschrift für die Kunde des Morgen-landes, 106.

Lafkioui M. (2011). Études de la variation et de la structuration linguistiques et sociolinguistiques en berbère du Rif. Cologne: Rüdiger Köppe.

Maas U. (2011). Marokkanisches Arabisch. Die Grundstrukturen. Munich: Lincom. 
Mettouchi A. (2011). "Démonstratifs et construction de la référence en kabyle”, in A. Mettouchi (ed.) "Parcours berbères". Mélanges offerts à Paulette Galand-Pernet et Lionel Galand pour leur $90^{\mathrm{e}}$ anniversaire. Cologne: Rüdiger Köppe, 469-484.

Ouali H. (2011). Agreement, Pronominal Clitics and Negation in Tamazight Berber. A Unified Analysis. London and New York: Continuum.

Penchoen Th G. (1973). Étude syntaxique d'un parler berbère (Ait Frah de l'Aurès). Naples: Centro di Studi Magrebini.

Rapold C. (2010). "Benificiaries and other roles of the dative in Tashelhiyt", in F. Zúñiga and S. Kittilä (eds.) Benefactives and Malefactives. Typological Perspectives and Case Studies. Amsterdam and Philadelphia: John Benjamins, 351-376.

Saa F. (2010). Quelques aspects de la morphologie et de la phonologie d'un parler amazighe de Figuig. Rabat: IRCAM (originally PhD Paris, 1995).

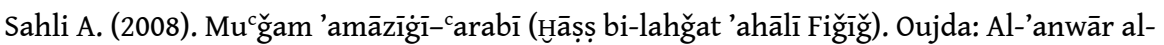
magribiyya.

Souag L. (2014). "The development of dative agreement in Berber: Beyond nominal hierarchies." Transactions of the Philological Society. doi: 10.1111/1467-968X.12049.

\section{NOTES}

1. I wish to thank Lameen Souag, who allowed me to read a preliminary version of his article on indirect object clitic doubling in Berber, and provided pertinent remarks on earlier versions of this article. I wish to express my lasting gratitude to the many Figuiguis who told the stories, recorded them for me, and helped me to write them down.

2. In addition, the recorded corpus contains one description of ancient marriage practices by $<\mathrm{B}>$ and a number of other women. This text was integrated in the counts of the K-corpus.

3. In Figuig, $i$ is homonymous with the locative preposition $i$ 'in'. The difference can be seen in pronominalized forms, where the locative preposition takes the form di-. Etymologically, the two prepositions are different. While the indirect object marker $i$ is $i$ everywhere in Berber, the locative preposition goes back to ${ }^{*} \mathrm{~g}$, well attested elsewhere in Berber, which through more or less regular sound change became $y>i$. In Figuig, $i$ (in both meanings) has amalgamated forms when followed by a semi-vowel or a high vowel. With $i$ and $y$ it becomes $i k k$ (in some varieties igg), with $u$ and $w$ it becomes $u k k$ (in some varieties $g g^{w}$ ), e.g. i irgazən > ikk rgazən 'to the men'; i urgaz > ukk rgaz 'to the man' (Kossmann 1997: 216-219).

4. The following abbreviations are used: AO: Aorist; As: Annexed State (état d'annexion); Do: direct object; DUR: durative; F: feminine; FOc: focus marker; FS: Free State (état libre); FUT: future; IMPTV: Imperative; IO: indirect object; IPV: Imperfective; M: masculine; NP: Negative Perfective; NR: the marker ad of the non-realized mood; PL: plural; PV: Perfective; SG: singular; SR: Subject Relative marker (so-called participle); vENT: ventive. Clitics belonging to the verbal clitic cluster are marked by $=$. For an analysis of the meaning behind these labels, see Kossmann (1997). The story tellers are identified by an anonymizing abbreviation between $<>$ following the example. At the time of the recordings, A, B, F and $\mathrm{O}$ were middle-aged and old women, $\mathrm{Z}$ a young woman, and D, $E$ and $Y$ (the latter only in dictated texts) young men. All story tellers cited in the article are from the village Zenaga, except $\mathrm{F}$, who is from the village Elmaiz.

5. This definition is inspired by the description of 'affected object' in Hausa in Frajzyngier \& Munkaila (2004). I do not keep to their terminology, which I find somewhat confusing. In Berber 
studies, characterizations of the function of indirect object are relatively rare, cf. however Bentolila (1981: 269) and especially the detailed exposition in Rapold (2010).

6. Verbs that imply a dialogue, such as sston 'to ask', are constructed with a direct object, however.

7. With one verb, this has become lexicalized. The verb $\gamma$ rəs 'to slaughter' takes an indirect object. Its basic meaning is 'to cut the throat', but the body part is hardly ever expressed.

8. fhəm in the cognitive sense of 'to understand' is constructed with a direct object, e.g. i-fhəm ayənn $n$ bnadəm 'he understands this man (direct object)' (Kossmann 1997: 418).

9. Indirect objects are found both when the object is the source and when it is the content, e.g. ləbda i-ttsəlla ukk unn $n$ nəhdərt 'he always heard (to) those words' $<\mathrm{D}>$.

10. tțir is a code-switch with Moroccan Arabic; the normal Figuig Berber word is abərdal.

11. There are no examples in the corpus of a construction with two pronominalized indirect objects with other verbs. I assume this is due to corpus restrictions.

12. While the construction is often mentioned in passing in descriptions of Berber varieties, only few authors consider it in a more elaborate fashion, esp. Penchoen (1973: 66-68), Cadi (2006: 149-152), Guerssel (1995); Ouali (2011: 129ff.).

13. Data from dictated texts, mainly by story teller $\langle Y\rangle$, have sometimes been used as supplementary evidence, but were not included in any of the counts. The K-corpus is also the basis of the discussions in Kossmann (2014; fc.-a; fc.-b).

14. The use of $f$ may be another archaism in Benamara's style. Fouad Saa (p.c.), who has the same dialectal background as Benamara and belongs to the same generation, informs me that he knows $f$ only from one set expression, and that $s$ is the variant he would use.

15. Of course, only sentences that have ini with a lexical indirect object were counted. While ini is the verb that is by far the most commonly attested with a lexical indirect object in the two corpora, this is not to say that the construction with a lexical indirect object is particularly frequent with this verb: in the $\mathrm{K}$ corpus, the number of attestations with ini without a lexical indirect object is more than twenty times the number of attestations with a lexical indirect object.

16. Only found in texts from one speaker, $\mathrm{Y}$, who dictated a number of stories to me.

17. There are too few instances of concrete inanimate indirect objects in the corpus to make any statement about them.

18. In exophoric uses, i.e., when referring to entities that are present in "the situation surrounding the interlocutors" (Diessel 1999: 94), ayu conveys proximal deixis and a(yə)nn distal deixis. In our narratives, both are used for anaphora, with certain preferences for one or the other form depending on the story teller; see Kossmann (fc.-a).

19. This sentence is pronounced without any hesitation in a single intonation contour. The story teller is one of the most experienced within our corpus. Thus, there is no reason to consider this unexpected use of doubling an error.

20. For a recent account which problematizes the notion of definiteness in Moroccan Arabic, see Maas (2011: 153ff.).

21. This analysis is comparable to that proposed by Mettouchi (2011: 482), who stresses the importance of common cultural knowledge in the usage of Kabyle "anaphoric" deictics.

22. Note that this does not imply that the king only has a single servant; a more interpretative translation would be 'and he said to one of his servants'. 


\section{ABSTRACTS}

In Figuig Berber, like in many other Berber languages, it is possible to express the indirect object by a lexical expression and by a pronominal clitic in the same sentence ${ }^{1}$. This construction, called "dative doubling" in the literature, is in variation with constructions that do not have a pronominal clitic. In this article, dative doubling is studied in two corpora, one written corpus (Benamara 2011), and one spoken corpus, collected by the author. It is shown that dative doubling is all but absent in the written corpus, while it is quite frequent in the spoken corpus. In the spoken corpus, there is a clear correlation with information structure. Dative doubling is only rarely found with indirect objects that express new information, while it appears more than half of the times when indirect objects express old information. In addition, it is obligatory when expressing old information with the verb ini 'to say'.

L'interaction du style, de la structure informationnelle et de la définitude : les objets indirects doubles dans les récits en berbère de Figuig

En berbère de Figuig, à l'instar d'autres langues berbères, il est possible d'exprimer l'objet indirect dans le même énoncé, et par une expression lexicale, et par un élément pronominal. Cette construction, connue par le terme "redoublement datif", entre en variation avec des constructions où l'expression pronominale fait défaut. Dans cet article, nous étudierons le redoublement datif dans un corpus écrit (Benamara 2011) et dans un corpus oral, recueilli par nous-mêmes. Nous démontrons que le redoublement datif est quasiment absent dans le corpus écrit, tandis qu'il est bien attesté dans le corpus oral. Dans le corpus oral, son emploi montre une corrélation assez claire avec la structure informative de la phrase. Tandis qu'il est très rare d'avoir le redoublement datif avec des objets indirects qui donnent des informations nouvelles, il se trouve dans plus de la moitié des objets indirects exprimant des informations anciennes. En outre, il s'avère obligatoire quand des informations anciennes sont exprimées avec le verbe ini 'dire'.

\section{INDEX}

Keywords: berber, Figuig, indirect object, dative, clitic doubling, information structure, written vs. orals styles

Mots-clés: berbère, Figuig, objet indirect, redoublement des clitiques, structure informative, style écrit et style oral

\section{AUTHOR}

\section{MAARTEN KOSSMANN}

LUCL/Universiteit Leiden 